\title{
A COMPARATIVE EVALUATION OF ROPIVACAINE HYDROCHLORIDE AND ROPIVACAINE HYDROCHLORIDE WITH DEXMEDETOMIDINE FOR CAUDAL EPIDURAL ANAESTHESIA IN PAEDIATRIC PATIENTS UNDERGOING ELECTIVE INFRAUMBILICAL SURGERIES
}

Preeti Goyal1, Satyendra Singh Yadav ${ }^{2}$, Priya Ranjan ${ }^{3}$, Bhanu Chaudhary4 4 , H. K. Chorasia ${ }^{5}$, Ashish Mathur ${ }^{6}$, V. K. D. Jain ${ }^{7}$

${ }_{1}^{1}$ Associate Professor, Department of Anaesthesia, Gajra Raja Medical College, Gwalior.

${ }^{2}$ Assistant Professor, Department of Anaesthesia, Gajra Raja Medical College, Gwalior.

${ }^{3}$ Senior Resident, Department of Anaesthesia, Gajra Raja Medical College, Gwalior.

${ }^{4}$ Professor, Department of Anaesthesia, Gajra Raja Medical College, Gwalior.

${ }^{5}$ Associate Professor, Department of Anaesthesia, Gajra Raja Medical College, Gwalior.

${ }^{6}$ Assistant Professor, Department of Anaesthesia, Gajra Raja Medical College, Gwalior.

${ }^{7}$ Senior Medical Officer, Department of Anaesthesia, Gajra Raja Medical College, Gwalior.

\begin{tabular}{l}
\hline ABSTRACT \\
BACKGROUND \\
The aim of this study is to compare the efficacy of ropivacaine hydrochloride and ropivacaine hydrochloride with \\
dexmedetomidine in caudal epidural anaesthesia for postoperative pain relief in paediatric patients undergoing elective \\
infraumbilical surgeries.
\end{tabular}

\section{MATERIALS AND METHODS}

A prospective randomised study was carried out, which included sixty paediatric patients between the ages of 2 - 8 years of ASA Grade I/II patients who underwent infraumbilical surgeries. Patients were randomly divided into two Groups R and RD of thirty patients each. Group R received ropivacaine $0.2 \% 1 \mathrm{~mL} / \mathrm{kg}$ with $0.5 \mathrm{~mL}$ normal saline, while Group RD received ropivacaine $0.2 \% 1$ $\mathrm{mL} / \mathrm{kg}$ with dexmedetomidine $2 \mathrm{mcg} / \mathrm{kg}$ diluted to $0.5 \mathrm{~mL}$ of normal saline. Duration of analgesia, duration of motor blockade, sedation and side effects were observed. The data obtained was subjected to statistical computation with analysis of variance and chi-square test using Statistical Package for Sciences (SPSS) version 10 for windows and value of $\mathrm{P}<0.05$ was considered significant and $\mathrm{P}<0.001$ as highly significant.

\section{RESULTS}

The demographic profile, intra- and post-operative block characteristics and cardiorespiratory parameters were comparable and non-significant in both the groups. However, duration of postoperative analgesia is significantly prolonged in RD group as compared to R group. Sedation score with dexmedetomidine were better and turned out to be statistically significant. Side effect profile was also comparable.

\section{CONCLUSION}

Dexmedetomidine is a better neuraxial adjuvant for providing adequate sedation and prolonged post-operative analgesia.

\section{KEYWORDS}

Dexmedetomidine, Ropivacaine, Caudal, Epidural, Paediatric, Infraumbilical.

HOW TO CITE THIS ARTICLE: Goyal P, Yadav SS, Ranjan P, et al. A comparative evaluation of ropivacaine hydrochloride and ropivacaine hydrochloride with dexmedetomidine for caudal epidural anaesthesia in paediatric patients undergoing elective infraumbilical surgeries. J. Evolution Med. Dent. Sci. 2017;6(14):1072-1076, DOI: 10.14260/Jemds/2017/232

\section{BACKGROUND}

Pain is an unpleasant sensory and emotional experience associated with potential tissue damage. "Postoperative pain relief in paediatric patients needs special attention due to their inability to express the severity and type of pain they are suffering. Significant pain from improper analgesia will not only cause unacceptable pain during procedure, but also produces pain memory." 2 So a programmatic approach of paediatric pain management has been used in recent years with the introduction of safe and effective techniques.

Financial or Other, Competing Interest: None.

Submission 20-01-2017, Peer Review 04-02-2017,

Acceptance 07-02-2017, Published 15-02-2017.

Corresponding Author:

Dr. Preeti Goyal,

N-12, Chetakpuri

Gwalior.

E-mail: drpreetiravigoyal@gmail.com

DOI: $10.14260 /$ jemds $/ 2017 / 232$
Caudal analgesia is a useful adjunct to general anaesthesia for lower abdominal surgeries in children, as it provides postoperative analgesia and reduces perioperative narcotic requirement.

It is a form of epidural analgesia, which was first described by Cathelin and Sicard of Paris. ${ }^{3}$

Single shot caudal block with bupivacaine is the most commonly used regional technique for intraoperative and postoperative pain relief in children. It has been proved that its efficacy in producing safe, reliable, efficient and long lasting analgesia. 4 Ropivacaine is another amide local anaesthetic, which has been reported to cause less motor block and less cardiotoxicity than bupivacaine, but producing similar duration of analgesia. ${ }^{5}$ Some studies showed that use of ropivacaine in caudal block causes a quicker onset and longer duration of action than bupivacaine. ${ }^{6}$

The main disadvantage with single shot caudal block with plain local anaesthetic is its short duration of action. To prolong the duration of analgesia and to reduce the intra- and 
post-operative analgesic requirements, many adjuvants have been investigated like Clonidine, Midazolam, S-Ketamine, Fentanyl, Dexmedetomidine, etc.

The anaesthetic and analgesic requirement get reduced to much extent by the use of alpha- 2 adrenergic agonist dexmedetomidine as an adjuvant, because of its analgesic properties and augmentation of local anaesthetic effects as they cause hyperpolarisation of nerve tissues by alteration of transmembrane potential and ion conductance at locus coeruleus in the brain stem.7-9 The stable haemodynamics and the decreased oxygen demand due to enhanced sympathoadrenal activity make alpha- 2 adrenergic agonists as very useful pharmacologic agents. ${ }^{10,11}$

Addition of dexmedetomidine to Ropivacaine increases the duration of analgesia produced by ropivacaine. This study has been carried out to compare the efficacy of caudal block with ropivacaine and ropivacaine with dexmedetomidine combination in paediatric lower abdominal surgeries.

\section{MATERIALS AND METHODS}

After obtaining approval from the Ethical Committee and written consent from the parent/guardians, this study was carried out in the Department of Anaesthesiology, GRMC, Gwalior. Sixty paediatric patients of ASA Grade I and II of either sex of age group 2 - 8 years scheduled for elective infraumbilical surgeries were divided into two Groups $\mathrm{R}$ and RD of 30 each.

A thorough preoperative evaluation was done including History, General and Systemic examination, Airway assessment and Spine. Baseline vital parameters were noted. Relevant laboratory investigations were done in all the patients. Study was performed in a double-blinded fashion.

Group R received Ropivacaine [0.2\%] $1 \mathrm{~mL} / \mathrm{kg}$ with $5 \mathrm{~mL}$ of normal saline. Group RD received Ropivacaine [0.2\%] 1 $\mathrm{mL} / \mathrm{kg}$ with dexmedetomidine $2 \mathrm{mcg} / \mathrm{kg}$ diluted to $0.5 \mathrm{~mL}$ of normal saline.

In the operation theatre, a good intravenous access was secured and monitoring devices were attached which included heart rate, Electrocardiograph [ECG], pulse oximetry $\left[\mathrm{SPO}_{2}\right]$, Non-Invasive Blood Pressure [NIBP] and respiratory rate. Induction of Anaesthesia was achieved with ketamine 1 $\mathrm{mg} / \mathrm{kg}$ body weight and was maintained with $50 \% 0_{2}+50 \%$ $\mathrm{N}_{2} 0$ mixture and $0.5-1 \%$ halothane using Jackson Rees circuit.

Patients were administered caudal block and drug administered according to the study group. Patient in Group $\mathrm{R}$ received ropivacaine [0.2\%] $1 \mathrm{~mL} / \mathrm{kg}$ diluted to $0.5 \mathrm{~mL}$ with normal saline. Patient in Group RD received [0.2\%] Ropivacaine $1 \mathrm{~mL} / \mathrm{kg}$ with dexmedetomidine $2 \mathrm{mcg} / \mathrm{kg}$ diluted to $0.5 \mathrm{~mL}$ with normal saline. Modified Bromage scale [0 = no block, 1 = inability to raise extended leg, 2 = inability to flex knee and $3=$ inability to flex ankle and foot] was used to measure the motor blockade effect at shifting $75,90,120$ and 180 minutes after block. Duration of postoperative analgesia was assessed by assessing pain intensity using FLACC score [0 = No pain, $1-3=$ Mild pain; $4-7=$ Moderate pain and $8-10=$ Severe pain] at 60, 120, 240 and 480 minutes after block. Grading of sedation was evaluated by a four-point sedation score [ 1 = Asleep, not arousable by verbal contact; 2 = Asleep, arousable by verbal contact; 3 = drowsy, not sleeping; 4 = Alert] at 75, 90, 120 and 180 minutes after block.

Cardiorespiratory parameters were monitored continuously; recordings were made every 5 minutes after which readings were recorded every 10 minutes till 1 hour. After 1 hour recordings were made at 2, 4 and 8 hours. Hypotension [defined as systolic arterial pressure falling more than $30 \% \mathrm{mmHg}$ from the baseline value] was treated with mephentermine. Heart rate less than $30 \%$ of baseline value was treated with I/V atropine $0.01 \mathrm{mg} / \mathrm{kg}$. Intravenous fluids were given as per body weight and operative loss requirement. During the surgical procedure, adverse events like nausea and vomiting, shivering, pruritus, etc. were recorded. The onset of pain [FLACC 4 or more] was managed with paracetamol suppository $40 \mathrm{mg} / \mathrm{kg}$ rectally. At the end of study, data was compiled systematically and analysed using analysis of variance and chi square test. Statistical Package for Social Sciences [SPSS] version 10. 0 for windows was used. Value of $\mathrm{P}<0.05$ was considered significant and $\mathrm{P}$ $<0.001$ as highly significant.

\section{RESULTS}

\begin{tabular}{|c|c|c|c|c|c|}
\hline \multicolumn{2}{|l|}{ Characteristics } & Total Study Sample & Group 'R' & Group 'RD' & P value \\
\hline \multicolumn{2}{|l|}{ Age (Months) } & $56.97( \pm 25.22)$ & $56.20( \pm 27.67)$ & $57.53( \pm 22.77)$ & 0.839 \\
\hline \multicolumn{2}{|l|}{ Sex (M:F) } & $49: 11$ & $24: 6$ & $25: 5$ & - \\
\hline \multicolumn{2}{|l|}{ Weight (Kgs) } & $14.11( \pm 2.44)$ & $14.16( \pm 2.35)$ & $14.06( \pm 2.53)$ & 0.875 \\
\hline \multirow{3}{*}{ Operations Performed } & Herniotomy & 25 & 13 & 12 & \\
\hline & Urethroplasty & 22 & 10 & 12 & \\
\hline & Others & 13 & 7 & 6 & \\
\hline Duration of Procedure [Minutes] & & $32.67( \pm 6.15)$ & $33.33( \pm 5.92)$ & $32.00( \pm 6.37)$ & 0.400 \\
\hline
\end{tabular}

\begin{tabular}{|c|c|c|c|c|}
\hline \multicolumn{2}{|c|}{ Study Variable } & Group 'R' & Group 'RD' & P value \\
\hline \multicolumn{2}{|c|}{ Duration of postoperative analgesia (Minutes) } & $279.00( \pm 46.26)$ & $795.00( \pm 39.02)$ & $<0.01^{* *}$ \\
\hline \multirow{6}{*}{ FLACC scores } & 60 Minutes later & $0.66( \pm 0.66)$ & $0.93( \pm 0.78)$ & 0.16 \\
\hline & 120 Minutes later & $1.53( \pm 0.94)$ & $1.56( \pm 0.63)$ & 0.87 \\
\hline & 240 Minutes later & $3.63( \pm 0.89)$ & $2.20( \pm 0.48)$ & $<0.01^{* *}$ \\
\hline & 480 Minutes later & $4.50( \pm 0.68)$ & $2.63( \pm 0.50)$ & $<0.01^{* *}$ \\
\hline & 720 minutes later & $5.66( \pm 0.48)$ & $3.66( \pm 0.48)$ & $<0.01^{* *}$ \\
\hline & $\begin{array}{l}\text { FLACC score at the time of } \\
\text { first analgesia request }\end{array}$ & $4.23( \pm 0.57)$ & $3.66( \pm 0.48)$ & $<0.01^{* *}$ \\
\hline \multicolumn{5}{|c|}{ Table II } \\
\hline
\end{tabular}




\begin{tabular}{|c|c|c|c|c|}
\hline \multicolumn{2}{|c|}{ Study Variable } & Group 'R' & Group 'RD' & P value \\
\hline \multirow{4}{*}{ Sedation Scores } & At time of shifting & $3.13( \pm 0.73)$ & $2.63( \pm 0.71)$ & $0.01^{*}$ \\
\cline { 2 - 5 } & 75 Minutes later & $3.50( \pm 0.50)$ & $3.06( \pm 0.74)$ & $0.01^{*}$ \\
\cline { 2 - 6 } & 90 Minutes later & $4.00( \pm 0.00)$ & $3.43( \pm 0.62)$ & $<0.01^{* *}$ \\
\cline { 2 - 6 } & 120 Minutes later & $4.00( \pm 0.00)$ & $4.00( \pm 0.00)$ & - \\
\cline { 2 - 6 } & 240 Minutes later & $4.00( \pm 0.00)$ & $4.00( \pm 0.00)$ & - \\
\hline
\end{tabular}

\begin{tabular}{|c|c|c|c|}
\hline Study Variable & Group 'R' & Group 'RD' & P value \\
\hline Duration of motor blockade (Minutes) & $106.83( \pm 27.80)$ & $101.00( \pm 26.04)$ & 0.405 \\
\hline \multicolumn{2}{|c|}{ Table IV } \\
\hline
\end{tabular}

\begin{tabular}{|c|c|c|c|c|}
\hline \multirow{2}{*}{ Complications } & \multicolumn{2}{|c|}{ Group 'R' } & \multicolumn{2}{c|}{ Group 'RD' } \\
\hline & Number & \% & Number & \% \\
\hline Nausea and Vomiting & & & 1 & 3.33 \\
\hline Hypotension & & & & \\
\hline Bradycardia & & & & \\
\hline Shivering & 3 & 10 & & \\
\hline Dyspnoea & & & & \\
\hline Headache & & & & \\
\hline Respiratory Depression & & & & \\
\hline Table V. Comparison of Side Effects and \\
Complications in Both the Groups \\
\hline
\end{tabular}

Patients who underwent were enrolled for the study and were randomly divided into two groups. The demographic profile of the patients in both the groups were comparable with regard to age, weight and sex. The mean duration of surgery was comparable in both the groups and was statistically insignificant [P $>0.05]$, Table No. I.

Addition of dexmedetomidine to ropivacaine as an adjuvant resulted in prolonged duration of analgesia [795.00 $\pm 39.02]$ as compared to ropivacaine alone [279 \pm 46.26$]$. Dexmedetomidine also resulted in reduced FLACC scores at $240,480,720$ minutes and at the time of first analgesia request as compared to ropivacaine alone. Duration of analgesia and FLACC scores turned out to be statistically significant values on comparison $[\mathrm{P}<0.05]$ Table No. II.

Modified Bromage scores and duration of motor blockade were statistically non-significant when compared in both the groups [P > 0.05], Table No. IV.

Dexmedetomidine is a popular sedative agent nowadays and similar findings were observed in our study as well. Mean sedation scores were significantly lower in RD Group as compared to Group $\mathrm{R}$ at the time of shifting at 75 minutes and 90 minutes after block, $[\mathrm{P}<0.01]$, Table No. III.

Table 5 shows the comparative incidence of various side effects in both the groups, which were observed in the intraand post-operative period. Only one patient in RD Group had vomiting, while 10 patients in Group R had shivering. We did not observe hypotension, headache and respiratory depression in any patient in either group.

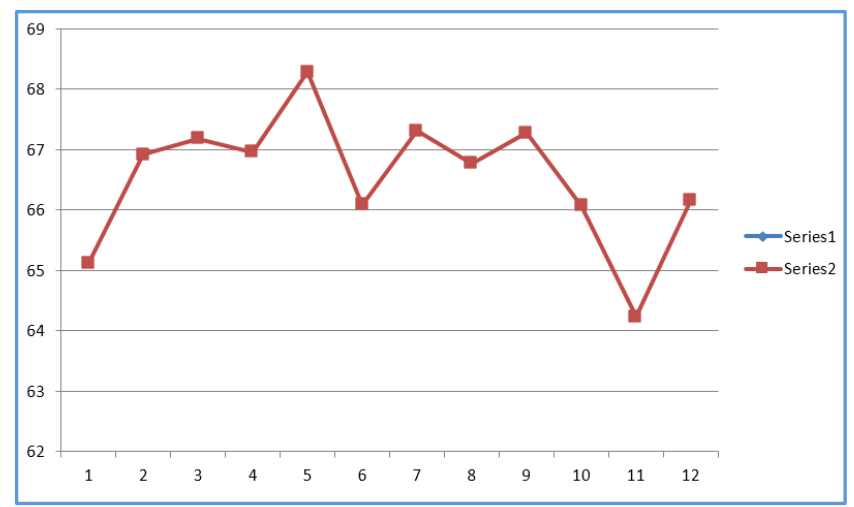

Mean Systolic Blood Pressure

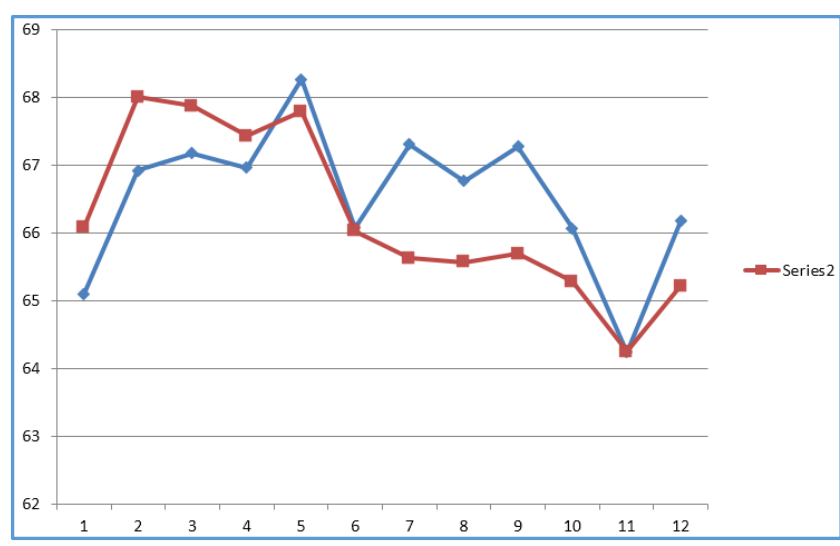

Mean Diastolic Blood Pressure

\section{DISCUSSION}

The main disadvantage with single shot caudal block with plain local anaesthetic is its short duration of action. To prolong the duration of analgesia and to reduce the intra- and post-operative analgesic requirements many adjuvants have been investigated like morphine, clonidine, dexmedetomidine, etc.

The use of opioids for neuraxial blockade is associated with various side effects such as respiratory depression, nausea, urinary retention and pruritus. So various alternatives including alpha-2 adrenergic agonists have been investigated. $12,13,14$

Epidural administration of these drugs is associated with sedation, analgesia, anxiolysis and sympatholysis. 15,16 
The faster onset of action of local anaesthetics, rapid establishment of sensory and motor blockade, prolonged duration of analgesia into postoperative period, dose sparing action of local anaesthetics and stable cardiorespiratory parameters make these agents as very effective adjuvants in regional anaesthesia. ${ }^{17,18,19}$

Caudal administration of dexmedetomidine resulted in better quality of sleep and a prolonged duration of arousable sedation and produces less incidence of emergence agitation. ${ }^{20,21}$

The present study was undertaken to compare the postoperative analgesic efficacy and duration of analgesia of ropivacaine alone and ropivacaine with dexmedetomidine combination in caudal block in paediatric patients. The demographic profile of our patients was comparable with respect to mean age, body weight, sex and duration of surgery. The results of the study have shown that the addition of dexmedetomidine $2 \mathrm{mcg} / \mathrm{kg}$ as an adjuvant to caudal ropivacaine not only prolongs the duration of analgesia, but also provides a good sedation level in postoperative period. The results are in accordance with various other studies.20,21 The results of our study clearly indicate the effectiveness of caudal dexmedetomidine, as it produced significant sedation in patients of RD group when compared with ropivacaine alone. Other studies also observed similar result. 22,23

Overall, the difference in sedation scores were significant statistically with administration of dexmedetomidine.

The RD Group showed visible superiority over R Group in various postoperative block characteristics like prolonged duration of analgesia, sedation scores and FLACC scores postoperatively.

The cardiorespiratory parameters as is evident from Figure 1 and 2 remained stable throughout the study period, which reaffirms the established effects of alpha- 2 agonists in providing a haemodynamically stable perioperative and postoperative period.

- As initially injection Ketamine was given to the subjects for sedation so that caudal block could be administered, there was a significant increase in pulse rate, systolic and diastolic blood pressure in the first 15 minutes in both the groups followed by a significant fall, which become similar to pre-induction values in the postoperative period. The side effect profile of the drug was quite favourable, as none of the patient in either group had profound sedation or respiratory depression which correlates very well with other studies.

- Only one patient in dexmedetomidine group had nausea and vomiting. One advantage of dexmedetomidine adjuvant noted was that 3 subjects in Group $\mathrm{R}$ had postoperative shivering, while none in patients receiving dexmedetomidine. The findings correlate with other studies. ${ }^{24,25}$

\section{CONCLUSION}

We conclude that dexmedetomidine when used as an adjuvant in paediatric caudal anaesthesia provides prolonged postoperative analgesia, better sedation and stable cardiorespiratory parameters.

\section{REFERENCES}

[1] Rajgopal MR. Pain basic considerations. Indian J Anaesthesia 2006;50(5):331-4.

[2] Berde R, Nema N, Minj B, et al. Comparative study of caudal ropivacaine and ropivacaine-clonidine combination in paediatric urogenital surgeries for post operative analgesia. JEMDS 2015;4(60):10477-87.

[3] Frolich MA, Caton D. Pioneer in epidural needle design. Anesth Analg 2001;93(1):215-20.

[4] Wolf AR, Valley RD, Fear DW, et al. Bupivacaine for caudal analgesia in infants and children: the optimal effective concentration. Anaesthesiology 1988;69(1):102-6.

[5] McClure JH. Ropivacaine. Br J Anaesth 1996;76:300-7.

[6] Ivani G, Mereto N, Lampugnani E, et al. Ropivacaine in paediatric surgery: preliminary results. Paediatr Anaesth 1998;8(2):127-9.

[7] Fukushima K, Nishimi Y, Mori K. The effect of epidurally administered dexmedetomidine on central and peripheral nervous system in man. Anaesth Analg 1997;84:S292.

[8] Pihlavisto M. Molecular pharmacology of alphazadrenoceptor agonists. Bailliere's Clin Anaesth 2000;14:247-60.

[9] Correa-Sales C, Rabin BC, Maze M. A hypnotic response to dexmedetomidine, an alpha-2 agonist, is mediated in the locus coeruleus in rats. Anaesthesiology 1992;76(6):948-52.

[10] Taittonen MT, Kirvela OA, Aantaa R, et al. Effect of clonidine and dexmedetomidine premedication on perioperative oxygen consumption and haemodynamic state. Br J Anaesth 1997;78(4):400-6.

[11] Buerkle H. Peripheral anti-nociceptive action of alpha 2 -adrenoceptor agonists. Bailliere's Clin Anaesth 2000;14(2):411-8.

[12] Filos KS, Goudas LC, Patroni O, et al. Haemodynamic and analgesic profile after intrathecal clonidine in humans. A dose response study. Anaesthesiology 1994;81(3):591-601.

[13] Chiari A, Lorber C, Eisenach JC, et al. Analgesic and haemodynamic effects of intrathecal clonidine as the sole analgesic agent during first stage of labor: a doseresponse study. Anaesthesiology 1999;91(1):388-96.

[14] Arain SR, Ruehlow RM, Uhrich TD, et al. The efficacy of dexmedetomidine versus morphine for postoperative analgesia after major inpatient surgery. Anaesth Analg 2004;98(1):153-8.

[15] Mauro VA, Brandao ST. Epidural clonidine or dexmedetomidine for post-colecystectomy analgesia and sedation. Rev Bras Anestesiol 2004;54(4):1-10.

[16] Gabriel JS, Gordin V. Alpha 2 agonists in regional anaesthesia and analgesia. Curr Opin Anaesthesiol 2001;14(6):751-3.

[17] Coskuner I, Tekin M, Kati I, et al. Effects of dexmedetomidine on the duration of anaesthesia and wakefulness in bupivacaine epidural block. Eur J Anaesthesiol 2007;24(6):535-40.

[18] EL-Hennawy AM, Abd-Elwahab AM, Abd-Elmaksoud $\mathrm{AM}$, et al. Addition of clonidine or dexmedetomidine to bupivacaine prolongs caudal analgesia in children. $\mathrm{Br} J$ Anaesth 2009;103(2):268-74. 
[19] Aantaa R, Kanto J, Scheinin M, et al. Dexmedetomidine, an alpha-2 adrenoceptor agonist, reduce anaesthetic recquirements for patients undergoing minor gynaecologic surgery. Anaesthesiology 1990;73(2):230-5.

[20] Saadawy I, Boker A, Elshahawy MA, et al. Effect of dexmedetomidine on the characteristic of bupivacaine in a caudal block in pediatrics. Acta Anaesthesiol Scand 2009;53(2):251-6.

[21] Anand VG, Kannan M, Thavamani A, et al. Effects of dexmedetomidine added to ropivacaine in paediatric lower abdominal surgeries. IJA 2011;55(4):340-6.
[22] Dobereiner EF, Cox RG, Ewen A, et al. Evidence based clinical update: which local anaesthetic drug for paediatric caudal block provides optimal efficacy with the fewest side effects? Can J Anaesth 2010;57(12):1102-10.

[23] Gertler R, Brown HC, Mitchell DH, et al. Dexmedetomidine: a novel sedative-analgesic agent. Proc [Bayl Univ Med Cent] 2001;14(1):13-21.

[24] Mato M, Perez A, Otero J, et al. Dexmedetomidine, a promising drug. Rev Esp Ansetesiol Reanim 2002;49(8):407-20.

[25] Bhana N, Goa KL, McClellan KJ. Dexmedetomidine. Drugs 2000;59(2):263-8. 